\title{
Educação ambiental na escola: a perspectiva estudantil sobre o meio ambiente e a propaganda ambiental na internet.
}

\author{
Fernanda Reis de Pinho Tavares - Licenciatura em Ciências Biológicas - UFMG \\ (feptavares@gmail.com)
}

\begin{abstract}
RESUMO
Este trabalho visa mostrar as idéias dos estudantes sobre um tema - a propaganda - refletindo como ela se insere na questão ambiental. Também abordamos como os alunos percebem questões como as relações, empresa, meio ambiente e sociedade. Foi realizado em uma oficina de Educação Ambiental, em uma escola particular de Lagoa Santa - MG, durante os meses de junho e julho de 2004. Analisaram-se sites de diversas empresas e ONG's (Organizações Não Governamentais). Em sua maioria os estudantes conseguiram posicionar-se criticamente em relação às entidades investigadas.
\end{abstract}

Palavras - chave: meio ambiente, propaganda, educação ambiental formal.

\section{INTRODUÇÃO}

\section{Trajetória profissional e delineamento da pesquisa}

Sou licenciada do curso de Ciências Biológicas na UFMG e meus primeiros contatos com Educação Ambiental (EA) aconteceram dentro de disciplinas na faculdade. A disciplina Instrumentação em Ecologia, por exemplo, tinha em sua ementa a criação de jogos que envolvessem educação ambiental. Além disso, em vários momentos do curso de Ciências Biológicas fomos sensibilizados pelos professores a inserir a EA na escola, sem contudo, muitas vezes oferecer-nos materiais para aprofundar a questão.

No primeiro semestre de 2003 também entrei em contato com a Educação Ambiental através de uma oficina que estava sendo oferecida na escola onde leciono. Esta escola preocupa-se com o desenvolvimento das múltiplas competências dos alunos oferecendo, assim, diversas oficinas englobando várias áreas de conhecimento como artes plásticas, teatro, literatura, xadrez, etc. Essas oficinas funcio nam como disciplinas da grade curricular e os estudantes podem escolher a qual pretendem cursar a cada semestre. Em uma das oficinas, a professora responsável ministrava aulas de reciclagem trabalhando com papel e com alguns seminários preparados pelos próprios alunos como: histórico do papel, o lixo, destinos do lixo na cidade, Projeto Manuelzão ${ }^{1}$. A oficina, assim, consistia basicamente em reciclar papel e construir um determinado produto, no caso, cadernetas. Esta caderneta deveria ter uma mensagem de conscientização ambiental, uma frase construída pelos estudantes, porque o material seria distribuído para pais de alunos que viessem conhecer o trabalho da escola. Durante este período, passei a assistir as aulas

\footnotetext{
${ }^{1}$ O projeto Manuelzão foi idealizado por um grupo de professores do Departamento de Medicina Preventiva e Social da Faculdade de Medicina da Universidade Federal de Minas Gerais, tendo iniciado suas atividades em janeiro de 1997, a partir do estágio em saúde coletiva- o internato rural. A proposta do Projeto Manuelzão é de envolver toda a população, as lideranças políticas, sociais e empresariais na melhoria das condições de saúde, meio ambiente e qualidade de vida da região da bacia hidrográfica do Rio das Velhas - MG.
} 
como estagiária para assumir como professora no semestre seguinte.

Minha verdadeira experiência em EA começou então quando assumi a oficina de reciclagem. $\mathrm{O}$ foco da oficina continuava o mesmo do semestre anterior: reciclagem de papel utilizando técnicas artesanais e construção de um produto (como cadernetas ou objetos de decoração, por exemplo). Tentei incluir algumas discussões sobre o que era o lixo, seu destino, entre outras coisas retiradas de alguns livros didáticos.

Senti-me extremamente frustrada no decorrer da oficina. Como estudante de biologia, a direção atribuía a mim a capacidade de trabalhar melhor os conteúdos que consideravam ligados à Educação Ambiental. Não conseguia produzir papel reciclado com as técnicas aprendidas no semestre anterior, nem desenvolver as tais questões que achavam que eu como bióloga daria conta. Percebi, na prática, que era necessário saber mais sobre Educação Ambiental. Não bastava apenas ser bióloga, arriscando tratar de temas como desenvolvimento sustentável e agenda 21, além de reciclar papel utilizando técnicas artesanais.

A oficina de reciclagem tornourse um dilema. Não acreditava que pudesse sensibilizar alguém para a causa ambiental nos moldes que me foram expostos e nas fontes pesquisadas até aquele momento.

Apenas depois de terminado o ano letivo e iniciando uma reflexão sobre a prática em EA (mais fruto do sentimento de frustração e das cobranças que surgiram em torno da oficina do que de uma decisão consciente de pensar sobre o trabalho), comecei a buscar a origem do meu conflito. No início do ano havia lido alguns capítulos do livro "Educação ou Adestramento Ambiental?", de Paula Brügger, que critica o modelo vigente de Educação Ambiental. Identifiquei me muito com o livro e com a proposta que ele trazia.

Paula Brügger levanta questões em relação a atividades classificadas como educação ambiental informal - "plante uma árvore no dia da árvore" -, ou práticas relacionadas ao Dia Mundial do Meio Ambiente. Essas atividades, que deveriam ser um "tema gerador", como diria Paulo Freire, sem o aprofundamento e questionamentos adequados, acabam reduzindo a questão ambiental a um aspecto puramente técnico, que mais se assemelha ao que Paula Brügger chama de "adestramento".

A partir desse momento comecei a refletir que uma oficina de Educação Ambiental deveria trabalhar conceitos ligados à ética, política, valores morais e questões ambientais. Ao trabalhar este último aspecto não deveria esquecer de nenhum dos outros. Queria contribuir de alguma forma para formar "cidadãos planetários", como diria Leonardo Boff, conscientes de seu senso crítico, agentes no seu processo educativo e em intervenções na comunidade a que pertencem.

A leitura de um segundo material, de Philippe Pomier Layrargues ${ }^{2}$, mostrou-me outras perspectivas da reciclagem. Decidi então que a partir daquele momento a oficina teria novo foco.

O presente trabalho é, portanto, o resultado da análise de textos e pesquisas feitos pelos alunos com os quais desenvolvi a oficina - uma turma de $4^{\circ}$ Ciclo $\left(7^{\mathrm{a}}\right.$ e $8^{\mathrm{a}}$ séries) - de uma escola particular de Lagoa Santa, MG. Dentro de uma nova perspectiva para a oficina, iniciamos com o tema "a importância da propaganda no mundo capitalista" e concluímos identificando como as empresas e ONG's que desenvolvem trabalhos ambientais apresentam-se, através de seus sites na internet.

\footnotetext{
${ }^{2}$ Layrargues, P.P. O cinismo da reciclagem In: Loureiro, Carlos F.; Layrargues, Philippe; Castro, Ronaldo. (orgs). Educação Ambiental: repensando o espaço da cidadania. Cortez Editora. 2002.
} 
Primeiramente o leitor vai encontrar uma revisão bibliográfica dos textos que influenciaram a minha concepção de educação ambiental e reciclagem. Tal revisão justifica-se devido à influência que teve na construção da minha concepção de EA. Em seguida, apresento o desenho metodológico da pesquisa, incluindo aspectos como o contexto no qual se desenvolveu a pesquisa, a forma como se deu a coleta de dados e o método usado na sua análise. Após esse desenho metodológico, apresento quais foram as categorias que surgiram da coleta de dados e a análise feita sobre estas categorias.

Este trabalho visa mostrar as idéias construídas pelos alunos sobre um tema, a propaganda, refletindo sobre como ela está inserida na questão ambiental. Um outro ponto abordado foi verificar como os alunos percebem a relação empresa, meio ambiente e sociedade, comparada com o papel das ONG's nessa dinâmica.

Esses temas emergiram durante a reestruturação da oficina. A proposta de trabalhar com o tema propaganda e o modo como ela está inserida na questão ambiental surgiu da importância que este tema tem na atualidade. Além disso, e talvez por influência de Layrargues (2002), que faz uma crítica à tão difundida reciclagem das latas de alumínio (e à reciclagem como um todo), optei por desenvolver um trabalho na oficina onde os alunos pesquisassem sobre como as empresas que dizem possuir trabalhos ambientais apresentam-se, o que elas fazem e se existem ou não interesses por trás desses trabalhos. Ou seja, eles deveriam além de fazer o levantamento das informações requeridas, realizar uma análise dessas informações e emitir, em alguns momentos, sua opinião pessoal.

\section{FUNDAMENTAÇ̃̃o TEÓRICA}

\section{Novas visões para a prática de Educação Ambiental em sala de aula}

\section{Refletindo sobre o tema "Educação ou adestramento ambiental?"}

A primeira leitura que me levou a pesquisar sobre as "novas" concepções de educação ambiental foi o livro de Paula Brügger "Educação ou Adestramento Ambiental?". A palavra "nova" no contexto aqui exposto refere-se a uma concepção diferente e mais abrangente do que as comumente conhecidas e que pareciam direcionar a maioria das práticas de EA que eu conhecia.

Em seu livro, Paula Brügger diferencia Educação para o Meio Ambiente de Educação Conservacionista. Na educação conservacionista os ensinamentos conduzem ao uso racional de recursos naturais e à manutenção de um nível ótimo de produtividade dos ecossistemas naturais ou gerenciados pelo homem. Enquanto que uma educação voltada para o meio ambiente implica em uma profunda mudança de valores, em uma nova visão de mundo, de acordo com a autora.

Temos notícia de que várias pessoas ligadas à prática de educação ambiental se detêm no primeiro aspecto levantado no parágrafo anterior. Realizam eventos isolados, como caminhadas para recolher o lixo em determinado local ou como a comemoração do Dia Mundial do Meio Ambiente, e se detêm nesse aspecto sem realizar discussões ou aprofundamento.

Ao definir treinamento/adestramento como "um tipo de instrução onde as pessoas são levadas a executar determinadas funções e tarefas, identificadas com um determinado padrão utilitarista-unidimensional de pensamento-ação", Brügger cita Marcuse (1983, p.32) quando diz que "as aspirações e os objetivos que por seu conteúdo transcendem o universo estabelecido da palavra e da ação são reduzidos a termos desse universo.”(Brügger, 1999, 
p.80).

Identifiquei a prática que vinha realizando na oficina de reciclagem e que era a proposta da escola com esse "adestramento". Havia pouca reflexão, pouco aprofundamento. E percebi que deveria mudar, formando cidadãos ambientais (formar no sentido amplo da palavra) e não adestrando-os em reciclagem.

Brügger também atribui a redução da educação ambiental às suas dimensões técnicas e naturais, à ligação do conceito de meio ambiente com as mesmas. Para reafirmar sua posição cita Gonçalves (1990, p.189):

"Um conceito chave para o debate em torno da questão ambiental é o de Meio Ambiente que, a rigor, não pode ser tratado nos parâmetros da tradição filosófica e científica que herdamos. A dicotomia cartesiana entre o homem e a natureza ainda continua a impregnar o conceito de meio ambiente com a sua redução à dimensão naturalista, isto é, a fauna, flora, ar e água ou simplesmente quando confundimos a problemática ambiental com poluição (grifos meus).” (Brügger, 1999, p.38).

Brügger afirma existir um consenso de que o conceito de meio ambiente deva ser amplo, abrangendo uma totalidade que inclui "os aspectos naturais e os resultantes das atividades humanas, sendo assim o resultado da interação de fatores biológicos, físicos, econômicos e culturais." (Brügger, 1999, p.51).

Ainda em relação à importância do conceito de meio ambiente para a questão ambiental podemos observar as perspectivas de Reigota (2002), que utiliza-se da teoria da "representação social" para relacionar meio ambiente e sociedade.

Reigota (2002, p.70) define as representações sociais como: "um conjunto de princípios construídos interativamente por diferentes grupos que através dela compreendem e transformam sua realidade". Segundo o autor, as representações sociais do termo meio ambiente definem qual será a prática do professor em educação ambiental.

A partir do exposto acima podemos inferir que as representações sociais podem ser analisadas em diferentes segmentos da sociedade (como, no caso deste trabalho, grupos empresariais e estudantes). Podemos, ainda, inferir que, por exemplo, a representação social de meio ambiente de uma ou de um grupo de empresas espelha sua política ambiental. E que um determinado grupo de estudantes percebe os discursos e as políticas ambientais inseridas na sociedade da qual é parte a partir da representação social de meio ambiente que possui.

Se a empresa visualiza o meio ambiente como algo externo a ela, revelando a dicotomia homem-natureza, seu universo de atuação possivelmente mostrará uma redução das suas políticas ambientais a soluções meramente técnicas. Este é um fato de extrema importância já que uma indústria sempre envolve trabalhadores, uma área no seu entorno e uma área de atuação.

Sobre esse assunto, um autor que aborda essa problemática no campo da reciclagem é Layrargues (2002,p.179). O autor mostra como a reciclagem, que deveria envolver e promover discussões, práticas, mudanças sócio-culturais e econômicas profundas, muitas vezes é reduzida à solução para o problema do lixo, no discurso empresarial.

\section{A resignificação da reciclagem}

Layrargues inicia seu artigo "O Cinismo da Reciclagem" destacando como o lixo é 
privilegiado como problema ambiental nos programas de EA na escola brasileira. Para isso foi criada a pedagogia dos 3R's, que norteia pedagógica e tecnicamente a questão do lixo.

Porém e fazendo uma analogia ao que já foi exposto sobre adestramento, esse tema é tratado de forma reducionista: prega-se a reciclagem, a colta seletiva do lixo...

"em detrimento de uma reflexão crítica e abrangente a respeito dos valores culturais da sociedade de consumo, do consumismo, do industrialismo, do modo de produção capitalista e dos aspectos políticos e econômicos da questão do lixo. E a despeito desta tendência pragmática, pouco esforço tem sido feito à análise do significado ideológico de reciclagem (...) e suas implicações para a educação ambiental reducionista, mais preocupada com a promoção de uma mudança comportamental sobre a técnica da disposição domiciliar do lixo (coleta convencional $\mathrm{x}$ coleta seletiva) do que uma reflexão sobre a mudança dos valores culturais que sustentam o estilo de produção e consumo da sociedade moderna." (Layrargues, 2002, p 180).

Iniciando uma reflexão sobre minha prática como docente, considero que a oficina que ministrava, em um momento anterior ao que fui exposta às referências que criticavam o modelo vigente de educação ambiental, baseava-se em práticas que podem ser identificadas com o texto acima.

No artigo de Layrargues retoma-se a discussão de como o que deveria ser um tema gerador (a reciclagem) é distorcido e acaba-se perdendo a dimensão ligada aos aspectos políticos e sociais.

A sociedade hoje é induzida ao consumo. A cada dia novidades entram pelas nossas portas por propagandas de várias formas. Propagandas essas, muitas vezes invasivas, que chegam até nós normalmente sem termos real consciência disso. São refrigeradores com design moderno e com água gelada na porta, celulares com câmeras e acesso à internet e muito mais. Por causa do avanço vertiginoso da tecnologia e da influência da mídia, os indivíduos acabam obrigados a consumir produtos que tornam-se obsoletos antes do tempo, já que cada vez mais tornam-se inúteis logo após sair das fábricas. Muitas vezes, os aparelhos ainda podem ser considerados funcionalmente perfeitos, no entanto, não são mais considerados tão bonitos ou mesmo modernos.

Layrargues (2002, p.184) corrobora a afirmativa anterior quando diz que "a moda e a propaganda provocam um verdadeiro desvio da função primária dos produtos. Ocorre que a obsolescência planejada e a descartabilidade são hoje elementos vitais para o modo de produção capitalista.".

Nossos adolescentes são bombardeados por ideais de moda e acessórios. A propaganda tornourse figura central no sistema capitalista já que sem ela é impossível transformar qualquer produto em objeto de desejo. Por isso, é fundamental trabalhar valores com estas gerações que já estão ou vão entrar no mercado de consumo. Como professores, devemos formar cidadãos que se preocupam mais com o ser do que com o ter. Tal fato explica a minha escolha por trabalhar com propaganda dentro do contexto de uma oficina de educação ambiental para a educação formal.

Em relação ao problema da cultura do consumismo, Layrargues $(2002$, p.185) cita Penna (1999):

“(...) como a sociedade moderna está impregnada de valores consumistas, 
tudo leva a crer que a tarefa da redução do consumo será árdua, pois será preciso reverter valores culturais enraizados, favorecidos pela invasão maciça da vida pública e doméstica.".

Em seu texto "Educação ambiental e (des)envolvimento", Meyer (1994) afirma que a sociedade, em geral, está mais ocidentalizada e quer consumir mais as necessidades criadas e impostas pelo capitalismo. Nesse contexto, as coisas perdem seus valores de uso e de troca e adquirem significados que "criam no imaginário desejos, fantasias e aspirações" (Meyer, 1994). A propaganda é a forma utilizada pelos fabricantes de realizar essa transformação, "resignificação" das coisas que nos rodeiam.

O consumismo exacerbado está intimamente associado a uma outra idéia, a descartabilidade. É gerado um ciclo sem fim ligado basicamente a interesses econômicos. Os objetos já saem de fábrica com durabilidade planejadamente reduzida, já que são necessários bens menos duráveis para levar o consumidor a comprar mais.

Apesar de termos uma cultura baseada no consumo, e sendo esta a plataforma de apoio do sistema capitalista, o discurso do empresariado precisa inserir a questão ambiental, já que os consumidores estão cobrando uma posição em relação a ela. Porém, observa-se uma deturpação de valores e inversão de estratégias. Não é interessante do ponto de vista capitalista a redução do consumo; assim, a reciclagem é imposta como a salvação do problema do lixo, sem, contudo, alterar os valores da sociedade movida pelo capitalismo. No entanto, numa visão mais crítica seria necessária uma redução dos padrões de consumo e da descartabilidade como prática precedente à reciclagem.

Com relação a essa questão, Layrargues (2002, p.188) cita Blauth (1996/97):

“(...) o equacionamento da problemática dos resíduos sólidos tem sido enfocado apenas na reciclagem, a qual tem a capacidade de produzir um efeito ilusório, tranqüilizante na consciência dos indivíduos, que passam a consumir mais produtos, sobretudo descartáveis, sem constrangimento algum, pois agora são recicláveis e, portanto, ecológicos.".

Assim, Layrargues (2002, p.189) conclui que a reciclagem..

“...camufla a crítica ao consumismo e, além de tudo, reforça as estratégias de concentração de renda. Recicla-se para não reduzir o consumo. Afinal, a reciclagem representa, além da salvação da cultura do consumismo, a permanência da estratégia produtiva da descartabilidade e da obsolescência planejada, permitindo a manutenção do caráter expansionista do capitalismo.”.

Assim, para a formação de um cidadão crítico é necessário compreender que por trás do discurso ecológico de grandes grupos empresariais há interesses econômicos e que mesmo as ONG's (Organizações Não Governamentais), como veremos no decorrer do presente trabalho, possuem interesses que vão além de conscientizar e lutar pela preservação do meio ambiente.

\section{DESENHO METODOLÓGICO}




\section{$O$ contexto da pesquisa}

A presente pesquisa foi realizada em uma escola particular de Lagoa Santa, MG. É uma escola pequena, que possui apenas uma turma de cada ciclo, e que adota uma pedagogia diferenciada de ensino. Esta pedagogia propicia ao aluno como laboratório de química, física e biologia, aulas de artes e oficinas. Para o Ensino Fundamental I e II, a escola adota o modelo de ciclos de dois anos, assim o $3^{\circ}$ Ciclo corresponde à quinta e sexta séries da pedagogia seriada e o $4^{\circ}$ Ciclo corresponde à sétima e oitava séries.

Entre as disciplinas curriculares inserem-se as oficinas que são direcionadas ao Ensino Fundamental II. A escola apresenta oficinas de Animação, Xadrez, Máscaras e de Reciclagem, a qual refere-se esse trabalho. Os alunos escolhem a oficina com a qual mais se identificam. Há uma divisão por ciclos, ou seja, as oficinas são ministradas para o terceiro e quarto ciclos separadamente.

A oficina de reciclagem foi ministrada com diferentes focos nos dois ciclos. Este trabalho refere-se à oficina ministrada para o $4^{\circ}$ Ciclo. A faixa etária dos alunos participantes da pesquisa era de $13-15$ anos e a turma da oficina em questão tinha 18 alunos. Esses alunos pertencem em sua maioria à classe média-alta, possuindo bom poder aquisitivo.

\section{O documento como instrumento de pesquisa}

A coleta de dados foi realizada a partir do material produzido pelos alunos, que consistia basicamente de textos escritos. Segundo Alves-Mazzotti (2004), documento é qualquer registro escrito que possa ser usado como fonte de informação.

\section{O desenvolvimento de um trabalho e metodologia de coleta de dados}

A oficina foi realizada no primeiro semestre de 2004. No entanto, este trabalho refere-se ao último módulo da oficina, que ocorreu entre os meses de junho e julho, perfazendo um total de 12 horas/aula. Assim, o presente trabalho representa um recorte da oficina. De acordo com a proposta da escola, os módulos anteriores da oficina priorizavam o reaproveitamento do papel não utilizado pela secretaria, contemplando a fabricação de produtos após a utilização de técnicas artesanais de reciclagem do mesmo. O foco principal era o aprendizado destas técnicas. As discussões eram esporádicas e visavam trabalhar com temas como lixo, coleta seletiva, reciclagem. E também grandes temas da EA, como a Agenda 21. Estes foram os principais conceitos abordados no primeiro módulo da oficina.

O planejamento do último módulo da oficina pode ser visto no ANEXO 1. Os materiais utilizados para análise correspondem aos textos produzidos pelos alunos ao final da primeira, terceira e quinta aulas do último módulo da oficina.

As aulas eram semanais e tinham duração de 100 minutos. A carga horária das atividades acima descritas variou entre 100 e 200 minutos, pois algumas extendiam-se até a aula seguinte.

Ao final de cada aula ou conjunto de 2 aulas os estudantes faziam registro escrito das informações discutidas ou levantadas por eles. Esses registros foram meu objeto de análise.

As concepções prévias dos estudantes foram analisadas a partir do texto que foi recolhido após o trabalho sobre as propagandas $\left(1^{\mathrm{a}}\right.$ aula). Neste texto, eles deveriam 
relacionar palavras como capitalismo, dinheiro, consumo, propaganda, mídia, descartabilidade, reciclagem. Esses textos compõem a primeira coleta de dados.

$\mathrm{Na} 3^{\mathrm{a}}$ aula, usando a internet como instrumento de pesquisa, os estudantes deveriam responder as questões abaixo relacionadas sobre várias empresas. A escolha dos sites teve o objetivo de abranger uma diversidade de discursos. As empresas escolhidas foram Samarco, Vale do Rio Doce, Natura, Sucatas.com (empresa virtual) e as ONG's Biodiversitas, Greenpeace e Fundação $\mathrm{O}$ Boticário. As respostas ao questionário abaixo constituíram a segunda coleta de dados para a presente pesquisa.

\section{Questões pesquisadas:}

1.Nome da empresa.

2.Produtos que vende ou serviços que presta no mercado.

3.Como a empresa/ONG se apresenta no site?

4.Que relação a empresa/ONG estabelece com o meio ambiente?

5.Que tipos de trabalhos ou atividades a empresa/ONG oferece para beneficiar o meio ambiente?

a)Como ela apresenta este trabalho?

b)Qual é a missão da ONG ou empresa?

6.Como esse trabalho beneficia a empresa? E como ele beneficia a sociedade? Explique.

7.A empresa tem algum slogan ligado aos seus trabalhos de me io ambiente?

a) Você considera o modo como a empresa se expõe uma propaganda? Explique.

b) A empresa tem parceiros? Quais? Quais suas relações com a empresa e com os trabalhos que apresenta?

8.Escreva uma carta para a empresa pedindo material de divulgação dos trabalhos ambientais para consulta. Exponha quem você é e o porquê do pedido.

$\mathrm{Na} 5^{\mathrm{a}}$ aula, os estudantes deveriam analisar como as empresas e ONG's pesquisadas se apresentavam, quais as diferenças entre as políticas ambientais levantadas, se existia um trabalho melhor ou pior, se aquelas atividades eram socialmente relevantes ou se apenas serviam para minimizar os impactos causados pela empresa. As conclusões foram registradas em forma de texto, material utilizado na terceira coleta de dados.

$\mathrm{Na} 6^{\mathrm{a}}$ aula, foi proposta uma auto avaliação e também uma avaliação do curso. Para levantar as concepções finais dos estudantes após o trabalho foi utilizada a análise de textos confeccionados pelos alunos nos moldes do realizado na primeira aula; porém, incluindo além das palavras iniciais, outras como: meio ambiente, projetos ambientais, conscientização, auto-imagem, sociedade. Tal material constitui a quarta coleta de dados.

$\mathrm{Na}$ maior parte do tempo os estudantes trabalharam em duplas, para permitir maior troca de informações entre eles. Apenas o texto final foi elaborado individualmente.

\section{Uma metodologia para análise dos dados}

Segundo Morais (1999), a análise de conteúdo é uma metodologia de pesquisa...

“... usada para descrever e interpretar o conteúdo de toda classe de documentos e textos. Essa análise, conduzindo a descrições sistemáticas, qualitativas ou quantitativas, ajuda a reinterpretar as mensagens e a atingir uma compreensão de 
seus significados num nível que vai além de uma leitura comum." (Morais, 1999, p.9).

A análise do conteúdo, principalmente a qualitativa, parte do pressuposto que um texto contém muitos significados. E esse método consiste de uma leitura pessoal do pesquisador sobre esses significados.

Em seu texto, Morais (1999) se refere à importância da explicitação do contexto como parte fundamental da análise de conteúdo. O contexto deve permear todo texto da pesquisa possibilitando ao leitor uma melhor compreensão do trabalho.

Morais (1999) considera a existência de duas vertentes nessa metodologia: a análise de conteúdo quantitativa e a análise de conteúdo qualitativa. $\mathrm{Na}$ análise de conteúdo quantitativa, os objetivos são pré-definidos e orientam as demais fases da pesquisa. Enquanto que, na análise de conteúdo qualitativa, os objetivos podem ser construídos durante a pesquisa e as categorias emergem durante o estudo.

Considero que a metodologia utilizada para a análise dos dados neste trabalho consiste em uma aproximação da metodologia conhecida como a análise de conteúdo qualitativa.

\section{APRES ENTAČ̃̃̃ DOS DADOS}

\section{oApresentando os dados da aula 1}

O primeiro grupo de dados refere-se aos textos dos estudantes que relacionavam diferentes termos como capitalismo, descartabilidade, mídia, propaganda, consumo ( $1^{\mathrm{a}}$ Aula). Refletem as discussões estabelecidas pelos mesmos e suas concepções em relação ao tema proposto. Podemos observar os seguintes grupos de relações nos textos:

A - A propaganda é indispensável para que o consumidor sinta-se atraído pelo produto. É também a base do sistema capitalista de lucro. descartabilidade.

B - A tecnologia está ligada ao desenvolvimento de produtos e à

C - A indústria produz embalagens descartáveis, pois não precisa preocupar-se com seu recolhimento e reaproveitamento. O consumo delas cresce, pois o consumidor não precisa preocupar-se com o destino de seu lixo.

D - A reciclagem resolve o problema do lixo, gera diretamente e indiretamente empregos e preserva os recursos naturais. produção.

E - A reciclagem é uma saída para as empresas não precisarem reduzir sua

Essas respostas apareceram em vários dos textos analisados. Algumas idéias presentes (como aquelas características do grupo A) foram encontradas em todos os textos. Outras, como as concepções representadas pelas letras B e D, apareceram, cada uma delas, em textos diferentes.

Em geral, o material produzido pelos alunos revela um consenso sobre a importância da propaganda no mundo capitalista. Porém, em relação à reciclagem, as percepções mostraram-se diferenciadas e algumas vezes contraditórias. Alguns alunos 
consideram a reciclagem uma solução para o problema do lixo enquanto outros a vêem como uma saída para a não-redução da produção de algumas empresas. Em nenhum momento nos textos analisados foram estabelecidas relações entre a reciclagem e a descartabilidade.

\section{○Apresentando os dados da aula 3}

Para a pesquisa feita na internet ( $3^{\mathrm{a}}$ Aula) optamos por analisar grupos de respostas elaboradas pelos estudantes para as questões. Os alunos realizaram a pesquisa na internet em duplas. Em relação às questões propostas para investigação, foram formados dois grupos de questões:

Grupo 1: - Como a empresa/ONG apresenta-se no site? - Que relação a empresa estabelece com o meio ambiente? - Que tipos de trabalhos ou atividades a empresa oferece para beneficiar o meio ambiente?

Grupo 2: - Como esse trabalho beneficia a empresa? - E como ele beneficia a sociedade? Explique. - A empresa tem algum slogan ligado aos seus trabalhos de meio ambiente? Você considera o modo como a empresa se expõe uma propaganda? Explique.

\section{GRUPO 1:}

Para o primeiro grupo de questões podemos apresentar as seguintes categorizações, através das tabelas 1, 2 e 3. Nas tabelas abaixo, as colunas "número de respostas relacionadas" referem-se a quantas vezes as categorizações apresentadas foram encontradas nas respostas dos alunos. Essas foram construídas a partir da análise dos trabalhos escritos:

Tabela 1: Tpjo de apresentação no site

\begin{tabular}{|c|c|c|}
\hline Grupos de empresas & Apresentação no site & $\begin{array}{c}\text { Número de respostas } \\
\text { relacionadas }\end{array}$ \\
$\begin{array}{c}\text { Biodiversitas, Greenpeace e } \\
\text { Fundação O Boticário }\end{array}$ & $\begin{array}{c}\text { Sempre possuem links para } \\
\text { filiação, fotos e notícias } \\
\text { ligadas à causa do grupo. }\end{array}$ & 6 \\
\hline $\begin{array}{c}\text { Samarco e Companhia Vale } \\
\text { do Rio Doce }\end{array}$ & $\begin{array}{c}\text { Trabalho inovador, buscam } \\
\text { criar o novo. }\end{array}$ & 2 \\
\hline $\begin{array}{c}\text { Natura e Sucatas.com } \\
\text { Expor várias de suas } \\
\text { atividades e áreas de atuação }\end{array}$ & 2 \\
\hline
\end{tabular}

De acordo com as respostas dos alunos em relação às informações presentes nos diferentes sites consultados, podemos perceber que cada grupo apresenta uma linguagem comum entre seus representantes, demonstrando semelhança ao se apresentarem na internet. 
Tabela 2: Relações que as empresas estabelecem com o meio ambiente

\begin{tabular}{|c|c|c|}
\hline Grupos de empresas e ONG's & Relação com o meio ambiente & $\begin{array}{c}\text { Número de } \\
\text { respostas } \\
\text { relacionadas }\end{array}$ \\
$\begin{array}{c}\text { Biodiversitas, Greenpeace, } \\
\text { Fundação O Boticário, } \\
\text { Sucatas.com }\end{array}$ & $\begin{array}{c}\text { Lutar pela preservação. } \\
\text { Frojetos ligados à preservação } \\
\text { do meio ambiente. }\end{array}$ & 5 \\
\hline $\begin{array}{c}\text { Natura, Companhia Vale do Rio } \\
\text { Doce, Samarco. }\end{array}$ & $\begin{array}{c}\text { Minimizar impactos causados } \\
\text { pelas atividades normais da } \\
\text { empresa. }\end{array}$ & 3 \\
\hline \multicolumn{2}{|c}{} \\
\hline
\end{tabular}

A coluna da tabela "Relação com o meio ambiente" refere-se ao modo como a empresa interage com o meio ambiente, quais são as suas ações em relação a ele.

Podemos observar que a percepção dos alunos para as atividades das ONG's em relação ao meio ambiente se dividem entre a luta pela preservação e o desenvolvimento de subsídios para a realização de projetos ligados ao meio ambiente. Por sua vez, as empresas concentram-se em projetos que visam minimizar os impactos que suas atividades (neste caso, principalmente de cunho extrativista) causam ao ambiente ao seu redor. A única exceção foi a Sucatas.com, que por ser uma empresa virtual, não produz impactos ao meio ambiente e nesta análise aproximou-se mais do perfil das ONG's nas suas relações com o meio ambiente.

Tabela 3: Atividades desenvolvidas pelas empresas/ONG's

\begin{tabular}{|c|c|c|}
\hline $\begin{array}{c}\text { Atividades desenvolvidas em } \\
\text { relação ao meio ambiente }\end{array}$ & Entidades envolvidas & $\begin{array}{c}\text { Número de respostas } \\
\text { relacionadas }\end{array}$ \\
\hline Projetos na área ambiental. & Todas & 4 \\
\hline $\begin{array}{c}\text { Financiamento e apoio a } \\
\text { projetos de outras entidades. }\end{array}$ & $\begin{array}{c}\text { Biodiversitas, Greenpeace, } \\
\text { Fundação O Boticário e } \\
\text { Sucatas.com }\end{array}$ & 3 \\
\hline Campanhas e protestos. & Biodiversitas e Greenpeace & 3 \\
\hline
\end{tabular}

Os projetos na área ambiental aparecem, nas respostas dos alunos, tanto para empresas quanto para as ONG's que eles investigaram na internet. Já os dois outros itens que constam na primeira coluna da tabela apareceram apenas no material daqueles alunos que consultaram sites de ONG's e também da empresa virtual. Sendo que realizar campanhas e protestos aparecem como atributos exclusivos das ONG's.

\section{GRUPO 2:}

As palavras mais encontradas nas respostas dos estudantes foram: conscientização, auto imagem, divulgar trabalho, arrecadação de fundos . Estas palavras referem-se aos benefícios que as atividades na área ambiental dão à empresa/ONG. 
Apareceram em praticamente todo o material produzido pelos estudantes que foi analisado, sendo que algumas delas foram encontradas juntas em diversos materiais.

Em relação às questões: "a empresa tem algum slogan ligado aos seus trabalhos de meio ambiente? Você considera o modo como a empresa se expõe uma propaganda?", podemos observar as seguintes respostas no material analisado:

Tabela 4: A propaganda no meio ambiental

\begin{tabular}{|c|c|c|}
\hline & $\begin{array}{c}\text { Número de duplas que } \\
\text { consideram o modo como a } \\
\text { empresa/ONG se expõe } \\
\text { uma propaganda }\end{array}$ & $\begin{array}{c}\text { Número de duplas que não } \\
\text { consideram o modo como a } \\
\text { empresa/ONG se expõe } \\
\text { uma propaganda }\end{array}$ \\
\hline $\begin{array}{c}\text { Empresa/ONG possui } \\
\text { slogan }\end{array}$ & 5 & 2 \\
\hline $\begin{array}{c}\text { Empresa/ONG não possui } \\
\text { slogan }\end{array}$ & - & 1 \\
\hline
\end{tabular}

A apresentação dos dados coletados pelos alunos na internet sobre a existência ou não de slogan nos sites das empresas e ONG's consultadas mostra que 7 duplas consideraram que elas possuem um slogan; são elas Samarco, Companhia Vale do Rio Doce, Sucatas.com, Biodiversitas, Greenpeace e Fundação O Boticário. Dentro deste universo há uma divisão de opiniões pessoais dos alunos em relação a considerar ou não a maneira como a empresa se expõe uma propaganda. Duas duplas consideraram que o modo de exposição da empresa/ONG não consiste de propaganda, argumentando que essa exposição é apenas para conscientização, ou uma forma de divulgar seus trabalhos e ajudar o meio ambiente. Cinco duplas, por sua vez, consideram o modo como a empresa/ONG se expõe uma propaganda, argumentando que isso ajuda a melhorar a imagem da empresa/ONG e que é também uma forma de conscientização e de divulgação dos seus trabalhos. Em uma primeira análise, podemos inferir que a palavra conscientização aparece portanto em dois contextos diferentes nas respostas dos alunos.

Apenas uma dupla considerou que a empresa não possui slogan, sendo esta a empresa Natura. Porém a dupla considera que o modo como a empresa æexpõe é uma propaganda, pois, de acordo com os alunos, o nome da mesma é mencionado o tempo todo no conteúdo do site.

Em relação aos benefícios que a sociedade poderia ter podemos perceber que a ocorrência de três idéias básicas entre os alunos:

- A sociedade ganha alguém capaz de atuar, "salvando" o mundo por ela;

- A partir das atividades ambientais de conscientização das entidades a sociedade começa a atuar em questões ambientais;

- A sociedade recebe reservas naturais e indígenas.

\section{- Apresentacão dos dados da aula 4}

A tabela 5 é resultado da categorização das respostas às questões: "Quais as diferenças entre os trabalhos das empresas apresentados aqui em sala? Existe uma atividade que possa ser considerada melhor ou pior? A ação da empresa funciona como forma de minimizar os prejuízos que ela causa ou é socialmente relevante?". 
Tabela 5: Conclusões dos alunos sobre os trabalhos das diferentes empresas.

\begin{tabular}{|c|c|c|}
\hline & Categorizações & $\begin{array}{c}\text { Número de } \\
\text { respostas inseridas }\end{array}$ \\
\hline \multirow[t]{2}{*}{ Sobre as diferenças } & Cada uma tem a sua área de atuação. & 6 \\
\hline & Não responderam esta questão. & 1 \\
\hline \multirow{2}{*}{$\begin{array}{l}\text { Existem trabalhos } \\
\text { melhores ou piores? }\end{array}$} & Não existem. & 6 \\
\hline & $\begin{array}{l}\text { Não existem, mas algumas empresas } \\
\text { fazem campanhas mais intensas. }\end{array}$ & 1 \\
\hline \multirow[t]{3}{*}{$\begin{array}{c}\text { Sobre a ação da } \\
\text { empresa }\end{array}$} & $\begin{array}{l}\text { Visa minimizar impactos por ela } \\
\text { produzidos. }\end{array}$ & 2 \\
\hline & São socialmente relevantes. & 0 \\
\hline & $\begin{array}{l}\text { Visam minimizar impactos, mas } \\
\text { também são socialmente relevantes }\end{array}$ & 5 \\
\hline
\end{tabular}

Os dados apresentados na tabela acima foram coletados após uma apresentação coletiva das pesquisas realizadas na internet. Cada dupla apresentou suas informações. Depois disso os alunos foram instigados a discutir e registrar suas idéias sobre as diferenças entre as atividades das empresas e ONG's em relação ao meio ambiente; se é possível julgar como melhor ou pior alguma das atividades divulgadas na internet e, finalmente, sobre a relevância das mesmas. Os alunos consideraram que não podemos classificar em melhor ou pior o trabalho de uma empresa e/ou ONG. Para as empresas, a maioria dos componentes da turma concorda que apesar de servir para minimizar os impactos da empresa no ambiente, seu trabalho também é socialmente relevante. Nenhuma dupla respondeu que considera o trabalho apenas socialmente relevante (mesmo aqueles que pesquisaram sobre ONG's), o que nos permite inferir que eles estão cientes da degradação que a atividade das empresas pode causar.

\section{Apresentação dos dados da aula 5}

Os últimos dados a serem apresentados referem-se à categorização dos textos produzidos pelos alunos na última aula da oficina. Podemos perceber as seguintes idéias permeando os textos:

A. A propaganda é indispensável para as empresas pois gera consumo, que aumenta a arrecadação. O consumo, por sua vez, gera maior descartabilidade. Vejamos como exemplo algumas respostas:

“... a mídia tem controlado as pessoas, por meio da propaganda, e faz com que elas tenham o desejo de consumir cada vez mais produtos e mais caros, fazendo com que as pessoas descartem seus produtos mais facilmente."

"Com as propagandas o consumidor se sente atraído e aumenta o consumo sobre o produto apresentado..."

"Hoje em dia a propaganda gera muito consumo desnecessário de produtos aumentando a descartabilidade." 
B. A propaganda, quando se refere aos projetos ambientais, funciona como forma de melhorar a imagem da empresa e também como forma de conscientizar a população:

"As grandes empresas, degradadoras do meio ambiente, para se auto promoverem, realizam projetos ambientais para a conscientização da população e sua auto-imagem."

C. As empresas geralmente gastam muito dinheiro em projetos e pesquisas na área ambiental. Porém não é possível saber se elas realmente acreditam nestas atividades ou se eles representam apenas uma forma de autopromoção. Como pode ser exemplificado na resposta abaixo:

"Porém, ultimamente, as empresas se conscientizaram mais em relação ao meio ambiente. Por isso, estas vêm gastando muito dinheiro em projetos ambientais, mas é impossível dizer se as empresas fazem as propagandas porque realmente acreditam nisso ou se é simplesmente para melhorar sua auto-imagem. $\mathrm{O}$ ideal seria conciliar os dois.".

D. Falta conscientização da população, que usa muitos produtos descartáveis:

"O que hoje em dia está em alta é a falta de conscientização das pessoas que usam muitos produtos descartáveis o que agrava muito o meio ambiente.”.

\section{ANÁLISE DOS DADOS}

As relações entre propaganda, consumo, reciclagem e descartabilidade - uma análise das primeiras discussões sobre o tema.

Em um primeiro momento podemos dizer que, para os alunos, há consenso quanto à importância da propaganda no meio empresarial (capitalista). Ela é indispensável para atrair o consumidor, despertar o desejo de adquirir um bem e também para a obtenção do lucro, já que o consumo é gerado a partir dela. Frases como as citadas abaixo apareceram com freqüência nos trabalhos analisados:

"Propaganda é a alma do negócio!".

"A mídia e a propaganda geram o desejo de comprar.".

Já a reciclagem aparece tanto com uma imagem positiva...

"A reciclagem é uma solução para o problema do lixo, gera empregos direta e indiretamente e funciona como uma espécie de férias para os recursos naturais.".

...quanto uma com imagem negativa:

"Nos projetos das empresas, elas reciclam apenas para mascarar o problema do lixo. O ideal seria reduzir a produção e fazer produtos mais duráveis o que não é bom para o capitalismo.”.

As percepções contraditórias em relação ao tema reciclagem podem ser fruto das influências dos conhecimentos prévios dos alunos sobre o tema. 
Um outro termo muito utilizado pelos alunos foi a descartabilidade. Ela aparece ligada ao aumento do consumo e à tecnologia. Porém, apenas um aluno referiu-se ao avanço da tecnologia como um agravante para o problema do lixo, argumentando que com o avanço da tecnologia temos a criação de novos produtos de maneira vertiginosa, o que, conseqüentemente, promoveria um maior descarte. Além disso, nos textos dos alunos a descartabilidade também está colocada como resultado do aumento da concorrência entre as diferentes marcas. Há consenso entre as diferentes respostas apresentadas com relação à afirmação de que o aumento da descartabilidade de produtos é o principal agravante da questão do lixo.

\section{Sobre como as empresas e ong's apresentam-se}

Segundo as respostas dos alunos presentes no questionário e informações, podemos perceber que cada grupo de empresas ou ONG's apresenta uma linguagem comum entre seus representantes, demonstrando semelhança ao se apresentarem na internet.

Sobre as atividades desenvolvidas e relações das empresas com o meio ambiente, observamos, através do levantamento feito pelos alunos, que estas estão reduzidas à sua dimensão técnica e o homem, que deveria fazer parte das questões ambientais, mostra-se externo, revelando uma dicotomia homem-natureza. A redução do meio ambiente à sua dimensão técnica considera possível a solução de problemas ambientais através exclusivamente do emprego e avanço da tecnologia. Essa solução de aparente eficiência pode, em longo prazo, agravar os problemas ambientais, já que em nenhum momento são discutidas as causas reais destes problemas.

Carvalho (1991), citada por Layrargues (2002,p.182), ao analisar o discurso ambientalista governamental brasileiro, aponta a existência de duas bases sobre a questão ambiental. O discurso ecológico oficial, enunciado pelo ambientalismo governamental, que representa a ideologia hegemônica e que se encarrega de manter os valores culturais presentes na sociedade. E o discurso ecológico alternativo, "proferido pelo ambientalismo original strictu sensu, corporificado pelo movimento social organizado", que representa uma ideologia contra hegemônica que dissemina valores contrários à ordem social e econômica existente.

Ao analisarmos as atividades e projetos ambientais levantados pelos estudantes, percebemos que eles alinham se ao discurso ecológico oficial. Pois para uma empresa não interessam aspectos como a redução de consumo, defendidos pelo discurso ecológico alternativo.

Já as ONG's apresentam projetos mais integrados à proposta do discurso ecológico alternativo; papel este já esperado, dado que são formadas e gerenciadas por membros da sociedade civil organizada. Apresentam-se sempre mostrando quais seus principais projetos, links para filiação, fotos e notícias ligadas à causa do grupo. Para a própria manutenção da $\mathrm{ONG}$, que geralmente não recebe apoio financeiro do governo, é fundamental a divulgação de idéias para garantir maior participação e maior arrecadação de fundos.

\section{ambiental}

O trinômio benefício-empresa/ONG's-sociedade e a propaganda no discurso 
A promoção da auto-imagem está colocada pelos alunos como o principal benefício para a empresa e/ou ONG, seguida da arrecadação de fundos para as suas atividades. A esta também se atribuem as justificativas em relação à propaganda, na qual a divulgação dos trabalhos da empresa melhora sua imagem

"A empresa não adquire nenhum benefício financeiro, mas com certeza melhora a imagem da rede de lojas O Boticário.”.

A palavra conscientização aparece diversas vezes nos textos produzidos pelos alunos. Podemos inferir que existem aí dois significados para esta palavra. O primeiro refere-se à conscientização como base para uma atuação da sociedade na causa ambiental. Ou seja, a conscientização seria uma forma de se adquirir os conhecimentos e informações necessários. Um segundo significado iguala a conscientização à idéia de divulgação, vinculando-a assim à propaganda publicitária.

Em relação à sociedade, permeiam dois papéis, um na qual é agente ativo que, à medida que se conscientiza, atua na preservação do meio ambiente. A sociedade também é vista como agente passivo, que recebe projetos de EA e reservas naturais ou indígenas das empresas que possuem atividades na área ambiental. Além disso, esses variados projetos e ações "salvam" o mundo para todos nós. As seguintes respostas dos estudantes podem exemplificar esta questão:

“...A sociedade se beneficia porque eles salvam o meio ambiente.".

“...a mesma beneficia a sociedade para que se possa salvar o meio ambiente fazendo com que a humanidade não morra mais rápido.".

“A sociedade recebe reservas naturais, indígenas, etc.”.

Revelam-se portanto preocupantes as concepções ligadas aos benefícios para a sociedade. No discurso dos alunos, a sociedade apresenta-se muitas vezes como agente passivo, que necessita dos projetos e atividades desenvolvidos pelas empresas consultadas para que através deles o mundo seja "salvo".

Em uma cultura onde se prega a comodidade, ter alguém para brigar por e solucionar nossas questões ambientais mostra-se mais seguro e confortável. Tira-se um "peso da consciência". Afinal, muitas vezes a concepção é de que existem várias coisas mais importantes no dia-a-dia do que lutar contra a destruição do meio ambiente, que dependendo da forma como é divulgada nos meios de comunicação, mostra-se como algo muito distante, externo ao ambiente urbano, de ação incipiente.

Nas respostas analisadas a partir dos trabalhos dos estudantes, percebemos que eles conseguem identificar que por trás das atividades voltadas para o meio ambiente podem existir interesses puramente econômicos e publicitários. Apesar de acharem fundamental o trabalho das ONG's, sabem que elas também arrecadam dinheiro através dessas mesmas atividades.

Mas ao mesmo tempo, são as atividades que tanto as ONG's como as empresas desenvolvem que contribuem para "salvar" o mundo. Ou seja, uma aparente contradição, já que as mesmas são parte desta sociedade. Por que na maioria das vezes nos colocamos externos aos grupos que pertencemos? Tratando-se de meio ambiente e questões ambientais 
é de fundamental importância um papel ativo da sociedade juntamente com ONG's, empresas e governo para buscar soluções mais humanitárias e ambientalmente corretas.

Em relação especificamente à questão de considerar o trabalho da empresa ou ONG uma propaganda, alguns grupos confirmaram este aspecto dado o modo como a empresa e/ou ONG se expõe exatamente por fazer divulgação de seu trabalho, contribuir para uma melhor inserção no mercado (já que a empresa melhora sua imagem) e conscientizar um determinado público-alvo:

"Sim. Porque a ONG coloca um slogan que te comove/convence a participar para a luta dos seus ideais.".

"Este site é uma propaganda, porque divulga seu trabalho e conscientiza o leitor a conservar o meio ambiente.".

No entanto, outros grupos em relação à questão de considerar o trabalho da empresa ou ONG uma propaganda, alguns grupos disseram que não se trata disso, pois consideram-na apenas uma forma de conscientização, de divulgar suas ações, ajudando assim, ao meio ambiente:

“- Não. É apenas uma conscientização para um mundo melhor.”.

\section{CONCLUSÕES}

A partir da análise das respostas podemos inferir que, para os alunos, a propaganda ambiental funciona basicamente do mesmo modo que a propaganda no mundo capitalista. No mercado comum observa-se que a propaganda tem vários objetivos além de estimular o consumo, como divulgação de ações, atividades, venda de uma imagem... Todas estas perspectivas mostram-se correlacionadas a aspectos como venda de idéias, disseminação de ideais, capacidade de provocar desejo e chamar a atenção. De acordo com a pesquisa, tanto no mundo capitalista quanto na esfera do meio ambiente vence aquela empresa que mostrar o melhor discurso nos meios de comunicação.

Quem divulga mais seus projetos ambientais é inserido num mercado de consumo preocupado com as questões ambientais, conscientiza (dissemina mais amplamente suas idéias, conseguindo maior número de pessoas dispostas a aderir à sua causa) e encontra mais financiadores. Mudam-se os "produtos", mas a base do processo continua equivalente.

Em sua maioria os estudantes conseguiram posicionar-se criticamente em relação às empresas investigadas. Além de considerarem relevantes os projetos ambientais, colocam que, por trás do discurso ecológico, há um benefício para quem o promove, esteja ele ligado à criação de uma imagem melhor diante do público consumidor ou à arrecadação de fundos para seus projetos.

É possível estabelecer inter-relações quando se analisa as questões que compõem o Grupo 2 (trinômio benefício-empresa/ONG-sociedade). Podemos exemplificar citando as respostas de grupos de alunos, que referem-se às duplas que trabalharam juntas durante a disciplina. As concepções colocadas abaixo apareceram em textos diferentes:

Grupo A: "O Greenpeace é uma entidade sem fins lucrativos, um trabalho voluntário. Fazendo do mundo onde moram um lugar melhor para se viver, cuidando 
melhor do meio ambiente. (...) Não acho que seja uma propaganda, acho que é uma conscientização da população a fazer o melhor para seu mundo.”.

Grupo B: "Provavelmente como o site divulga os trabalhos deve haver uma comissão. Conscientizando e fazendo projetos, mostrando que a reciclagem é muito importante e ajudando a preservar o meio ambiente. (...) Não, eles só querem mostrar seu trabalho e ajudar ao meio ambiente.".

Ambos os grupos colocaram que as empresas não estão beneficiando-se ao realizar suas atividades. E os dois afirmam que a fala da empresa não constitui propaganda.

Os demais grupos posicionaram-se de maneira crítica acerca dos benefícios da empresa e foram unânimes em considerar o modo de expor, no site, uma propaganda com teor publicitário, porém dissimulada:

Grupo C: "Isso [os projetos ambientais] permite à empresa prevenir-se de riscos, além de reduzir custos, aprimorar processos e explorar novos negócios voltados para a sustentabilidade ambiental, favorecendo a sua inserção no mercado. (...) Consideramos uma propaganda, pois nenciona o nome da empresa em todos os links. De certa forma ela se glorifica passando a mensagem: se você usar a Natura não prejudicará o meio ambiente.”.

Grupo D: "A Vale do Rio Doce é uma empresa muito grande e que degrada o meio ambiente. Se ela fala que tem uma consciência de preservação do meio ambiente, é como se fosse uma máscara para o que ela faz. (...) Sim, pois a Vale degrada ao meio ambiente e para mascarar a sua ação ela faz trabalhos sociais e ambientais promovendo a empresa.".

\section{Sobre as concepções finais}

Apresentamos por fim a análise dos textos finais da oficina com o tema propaganda. A idéia de que a propaganda é indispensável para o sistema capitalista, pois leva ao consumo, que, por sua vez, leva ao lucro, permanece em todo material analisado. Existe também um aparente consenso da relação deste aumento de consumo com a descartabilidade.

"Para as empresas, a propaganda é essencial para atrair o consumidor que trás o dinheiro para ela.".

"A degradação do meio ambiente tem aumentado muito devido a descartabilidade; a mídia tem controlado as pessoas, por meio da propaganda, e faz com que elas tenham o desejo de consumir cada vez mais produtos e mais caros, fazendo com que as pessoas descartem seus produtos mais facilmente.".

"Hoje em dia, a propaganda gera muito consumo desnecessário de produtos que leva a uma maior descartabilidade.".

Talvez pela maneira como foi conduzida a oficina, a palavra reciclagem não tenha aparecido em nenhum dos textos finais. Desviamos o foco da reciclagem para uma 
análise mais abrangente do discurso ambiental das empresas/ONG's.

A propaganda, quando utilizada pelas empresas/ONG's em um contexto ambiental, aparece tanto como uma forma de melhorar a imagem da empresa quanto como uma forma de conscientização da população:

"Essas propagandas são usadas pelas empresas, também para "montar" sua auto-imagem. Elas usam seus projetos ambientais e projetos de conscientização para fazêlo. Existe propaganda dentro desses também..".

"Para garantir uma boa imagem as empresas fazem projetos ambientais utilizando de propaganda para se beneficiar.".

Em relação às empresas que fazem projetos ambientais, alguns alunos colocaram que existe um caráter dúbio. As empresas gastam muito dinheiro em pesquisas e projetos ambientais, porém não se pode afirmar se isso é fruto de uma maior conscientização das mesmas porque acreditam nesses projetos, ou se os realizam apenas para criar uma imagem mais positiva da empresa:

"Porém, ultimamente, as empresas se conscientizaram mais em relação ao meio ambiente. Por isso, estão gastando muito dinheiro em projetos ambientais, mas é impossível dizer se as empresas fazem as propagandas ambientais porque realmente acreditam nisso ou se é simplesmente para melhorar sua auto-imagem.”.

As respostas revelam ainda a presença de uma sociedade "inconscientizada", o que muitas vezes agrava os problemas ambientais.

"O que hoje em dia está em alta é a falta de conscientização das pessoas (...).”.

O termo sociedade permanece ausente na maioria dos textos finais. Podemos inferir que talvez seja reflexo de uma sociedade mais ausente, passiva, à parte das questões ambientais. É interessante notar que em nenhum momento o termo "nós" foi utilizado. Tal fato revela que os alunos não se incluem nessa sociedade. Parece que nas respostas analisadas, os alunos colocam-se sempre como alguém que está "olhando para" e não "inseridos em" uma sociedade.

\section{COMENTÁRIOS FINAIS}

Durante o desenvolvimento do trabalho, ao analisar as categorias de dados e os textos finais, surpreendi-me com as percepções que os alunos tiveram sobre o tema abordado. Apesar de considerar que eles não estavam engajados ou motivados em alguns momentos do projeto, o resultado final mostrou-me que houve um bom aproveitamento dos temas discutidos.

Falhas? Elas sempre existem. Uma falha foi não desenvolver a contradição do tema reciclagem e como sua defesa pelas empresas está ligada a interesses econômicos. Porém sabemos que no universo de sala de aula as variáveis são infinitas e muitas vezes os temas colocados tomam caminhos não previstos inicialmente.

Foi extremamente interessante perceber como os alunos conseguiram posicionar-se criticamente em relação ao discurso das diversas empresas/ONG's 
investigadas. Em um contexto cultural marcado pela massificação de idéias é gratificante reconhecer que o público com o qual se está trabalhando tem uma percepção crítica do mundo.

A análise dos trabalhos mostrou-me uma questão que talvez mereça estudos posteriores: o olhar externo de grupos para com a sociedade e também com o meio ambiente. A não inserção do grupo de alunos que foi o universo da pesquisa é preocupante. Como mudaremos os valores de uma sociedade se aparentemente o grupo que trabalhamos considera-se externo a ela?

Este "sentimento de externalidade" pode ser fruto dos valores extremamente individualistas que estão presentes em nossa sociedade. Estes valores podem ser percebidos a todo momento no contexto escolar, como quando os estudantes negam-se a discutir uma determinada questão em grupo ou simplesmente trabalhar com ou ajudar um colega.

Uma educação verdadeiramente ambiental deve preocupar-se com esse sentimento de grupo. Para a organização de uma sociedade ativa em todos os seus sentidos, desde politicamente até a abordagem da questão ambiental, é necessária a formação de grupos. E que entre estes, exista respeito mútuo e que vejam por trás dos discursos de cada um, uma causa comum, seja ela, por exemplo, o debate sobre o destino do lixo ou sobre a pena de morte.

\section{REFERÊNCIAS BIBLIOGRÁFICAS:}

ALVES-MAZZOTTI, A.J. \& GEWANDSZNAJDER,F., $O$ método nas Ciências Naturais e Sociais - Pesquisa Qualitativa e Quantitativa, Pioneira, 2004.

BLAUTH, P. Rotulagem ambiental e consciência ecológica. Debates Socioambientais, São Paulo, 2(5): 10-12, 1996/97.

BRÜGGER, P. Educação ou adestramento ambiental? Letras Contemporâneas, 1999.

GONÇALVES, C.W.P. Extensão universitária e meio ambiente: a difícil relação entre o saber e o fazer. In: Textos básicos do "IV Seminário Nacional sobre Universidade e Meio Ambiente”, Florianópolis, Editora da UFSC, p.187204, 1990.

LAYRARGUES, P.P. O cinismo da reciclagem in Educação Ambiental: repensando o espaço da cidadania. Cortez Editora. 2002

MARCUSE, H. A ideologia da sociedade industrial - o homem unidimencional, Rio de Janeiro, $6^{\mathrm{a}}$ ed, Zahar, 1982.

MEYER, M.A.A. Educação Ambiental e (Des)envolvimento. Ciência \& Ambiente, [s.1.], n.8, p.53-70, jan-jul,1994.

MORAIS, R. Análise de conteúdo. Educação, n.37, p. 7 - 32, mar, Porto Alegre, 1999.

PENNA,C.G. $O$ estado do planeta: sociedade de consumo e degradação ambiental. Rio de Janeiro, Record,1999.

REIGOTA, M. Meio ambiente e representação social, Col. Questões de Nossa Época, Vol.41, Cortez Editora, 2002. 


\section{$\underline{\text { ANEXO 1 }}$ \\ OFICINA DE EDUCAÇÃO AMBIENTAL - Programa (4' Ciclo)}

1'Aula: Trabalho com propaganda.

-Alunos trazem propagandas escolhidas por eles em casa;

-Discussão dos principais temas relacionados: consumismo, capitalismo, lucro, bens descartáveis, etc...

-Produção textual(primeiro material para análise).

$2^{\mathbf{a}}$ Aula: Apresentação dos textos feitos na aula anterior.

$3^{a}$ Aula: Pesquisa na Internet (segundo material para análise):

-Como as empresa que se dizem ecologicamente corretas se expõe?

- Como as empresas que reciclam seus produtos se expõe?

-Escrever para as empresas pedindo material de consulta.

-Investigar os conceitos ligados a propagandas ecológicas.

- Comparar com sites de unidades de conservação.

4aAula: Visita à Soeicom (empresa que fabrica cimento e tem um Centro de Convivência Ambiental na cidade de Lagoa Santa):

- Como a empresa trabalha?

- Como ela faz divulgação do seu trabalho?

- Em que isso favorece a empresa?

- Em que favorece a sociedade?

5aAula: Análise do material e informações coletadas.

- Terceiro material para análise.

6 Aula: Apresentação dos trabalhos para a turma e conclusão.

- Ouarto material para análise. 